\title{
PENGARUH PEMAKAIAN KB IUD TERHADAP TERJADINYA POL YMENORRHEA PADA WANITA USIA SUBUR
}

\author{
Sulami ${ }^{1}$, Nabhani $^{2}$
}

\begin{abstract}
Polymenorrhea is a hormonal disorder by the age of the corpus luteum shortened so that the menstrual cycle becomes shorter. IUD (Intra Uterine Device) or is a tool made of smooth plastic metal usually copper or copper salts made in various forms. How it works is as follows when IUD is located in the womb there was a change in indometrium resulting in damage (lysis) of spermatozoa that can fertilize the ovum. This procedure will affect the menstrual cycle of woman which is called polymenorrhea.

This study aimed to determine the effect of the use of IUD on the incidence of polymenorrhea in women of childbearing age.

This type of research isanalytic, research with cross sectional approach. Results: The results of the study showed that IUD users as many as 18 people (60\%), while the womans who do not used IUD or have history of using IUD as many as 12 peoples (40\%). IUD users who experienced polymenorrhea were 4 peoples $(13.3 \%)$ It can be concluded that there was no influence between the use of IUD with the incidence polymenorrhea. The respondents with a significance level used is $95 \%$ then the critical limit of 0.05 , while the result $p=0.079$.
\end{abstract}

Keywords: IUD, polymenorrhea, Women of childbearing age.

\section{PENDAHULUAN}

Laju pertumbuhan penduduk di Indonesia senantiasa mengalami peningkatan. Hal ini tercermin dari hasil sensus penduduk 2010, Indonesia menunjukkan gejala ledakan penduduk. Jumlah penduduk Indonesia tahun 2010 tercatat 237,6 juta jiwa dengan laju pertumbuhan $1,49 \%$ pertahun, sementara pada tahun 2008 masih tercatat 288,53 juta jiwa. Laju pertumbuhan penduduk ini jika tetap pada angka itu, pada 2045 jumlah penduduk Indonesia diperkirakan mencapai 450 juta jiwa. Peningkatan penduduk yang tinggi ini akan mengakibatkan permasalahan jika tidak dikendalikan. Upaya untuk mengatasi ledakan jumlah penduduk tersebut salah satunya adalah melalui program Keluarga Berencana (KB).

Keluarga Berencana menurut WHO
(Word Health Organization) Expert Committee 1970 adalah tindakan membantu individu atau pasangan suami istri untuk menghindari kelahiran yang tidak diinginkan, mendapat kelahiran yang memang diinginkan, mengatur interval diantara kehamilan, mengontrol waktu saat kelahiran dalam hubungannya dengan umur suami istri, menentukan jumlah anak dalam keluarga (Anggraini, 2012).

IUD atau biasa disebut Intra Uterin Divice atau alat kontrasepsi dalam rahim (AKDR) adalah alat yang terbuat dari plastik halus logam biasanya tembaga atau garam tembaga dibuat dalam bermacam bentuk. Adapun cara kerjanya adalah dengan adanya alat ini di dalam rahim terjadilah perubahan pada endometrium yang mengakibatkan kerusakan (lysis) dari spermatozoa sehingga tidak 
dapat membuahi sel telur (Arintowati, 2013).

Polimenorrhea adalah siklus menstruasi yang lebih pendek dari pada biasanya yaitu kurang dari 21 hari, sedangkan jumlah perdarahan relatif tetap. Polimenorrhea merupakan gangguan hormonal dengan usia korpus luteum memendek sehingga siklus menstruasi pun menjadi lebih pendek (Manuaba, 2010).

Berdasarkan

Rencana

Pembangunan Jangka Menengah (RPJM) tahun 2004-2009 Departemen Kesehatan mencanangkan salah satu rencananya dalam meningkatkan metode pemakaian IUD di Indonesia pada tahun 2012. Rincian pengguna kontrasepsi adalah suntik 3.007.555 peserta $(56,88 \%)$, pil 824.502 peserta $(15,59 \%)$, Intra Uterine Devices (IUD) 460.128 peserta $(8,70 \%)$, implant 537.385 peserta $(10,16 \%)$ dan Medis Operatif Wanita (MOW) 289.549 peserta $(5,48 \%)$, Medis Operatif Pria (MOP) 57.387 peserta (1,09\%), kondom 110.837 peserta (2,10\%) (Departemen Kesehatan, 2012).

Berdasarkan hasil studi pendahuluan yang dilakukan oleh penulis di Puskesmas Mojolaban Kabupaten Sukoharjo, data yang didapat di Klinik Ibu dan Anak (KIA) meliputi pengguna KB sejumlah 536 wanita dan masing-masing pengguna suntik sebanyak 200 wanita $(37 \%)$, pil 123 wanita $(23 \%)$, implant 87 wanita (16\%), kondom 72 wanita (13\%), MOW 24 wanita (4\%)dan IUD sebanyak 30 wanita (6\%).

\section{TUJUAN PENELITIAN}

1. Tujuan Umum

Penelitian ini bertujuan untuk mengetahui pengaruh pemakaian KB IUD terhadap terjadinya polymenorrhea pada wanita usia subur di Puskesmas Mojolaban Kabupaten Sukoharjo.
2. Tujuan Khusus

a. Untuk mengetahui wanita yang memakai KB IUD dan yang mempunyai riwayat memakai KB IUD.

b. Untuk mengetahui kejadian polymenorrhea pada wanita pemakai KB IUD dan yang mempunyai riwayat memakai KB IUD.

C. Untuk menganalisa pengaruh terjadinya polymenorrhea pada wanita usia subur yang menggunakan KB IUD

\section{DESAIN PENELITIAN}

Jenis penelitian yang digunakan adalah penelitian analitik dengan pendekatan cross sectional. Instrumen penelitian yang digunakan untuk mengumpulkan data berupa checklist (daftar pertanyaan). Analisa data yang digunakan adalah Analisis Bivariat untuk menguji hubungan antara masing-masing variabel bebas dan variabel terikat. Penelitian ini menggunakan $U j i$ chi kuadrat $\left(x^{2}\right)$ dengan taraf signifikansi yang digunakan adalah 95\% maka batas kritis 0,05 .

\section{POPULASI, SAMPEL, DAN TEHNIK SAMPLING}

Populasi yang digunakan dalam penelitian ini adalah semua akseptor KB IUD sebanyak 30 ibu di Puskesmas Mojolaban Kabupaten Sukoharjo. Pengambilan sampel untuk pengguna IUD menggunakan tehnik Purposive sampling.

\section{HASIL PENELITIAN}

Berdasarkan penelitian yang telah dilakukan didapatkan karakteristik responden sebagai berikut :

1. Karakteristik responden 
Tabel 1.

Distribusi Frekuensi Karakteristik Responden Berdasarkan Umur, Pendidikan dan Perkerjaan

\begin{tabular}{cccc}
\hline Karakteristik & Kategori & $\mathrm{f}$ & $\%$ \\
\hline Umur & $<20$ th & 2 & 7 \\
& $20-35$ th & 15 & 50 \\
Pendidikan & $>35$ th & 13 & 43 \\
& SD & 8 & 27 \\
& SMP & 7 & 23 \\
& SMA & 10 & 33 \\
& Diploma & 3 & 10 \\
& Sarjana & 2 & 7 \\
Pekerjaan & IRT & 6 & 20 \\
& Buruh & 5 & 17 \\
& Swasta & 13 & 43 \\
& Wiraswasta & 2 & 7 \\
& PNS & 4 & 13 \\
\hline
\end{tabular}

Berdasarkan tabel 1. diketahui bahwa responden paling banyak pada karakteristik umur adalah pada kategori umur 20-35 tahun yaitu sebanyak 15 orang (50\%) sedangkan yang paling sedikit berusia $<20$ tahun sebanyak 2 orang (7\%). Pada karakteristik pendidikan diketahui juga bahwa responden paling banyak berpendidikan SMA sebanyak 10 orang (33\%) sedangkan yang paling sedikit berpendidikan sarjana sebanyak 2 orang $(7 \%)$. Sedangkan pada karakteristik pekerjaan responden paling banyak adalah sebagai pegawai swasta sebanyak 13 orang (43\%) dan pekerjaan yang paling sedikit adalah wiraswasta sebanyak 2 orang $(7 \%)$.

2. Hasil Analisis Univariat

Tabel 2.

Distribusi Frekuensi Responden Berdasarkan Pemakai Alat Kontrasepsi IUD dan Kejadian Polymenorrhea

\begin{tabular}{lccc}
\hline \multicolumn{1}{c}{ Karakteristik } & $\begin{array}{c}\text { Kate } \\
\text { gori }\end{array}$ & $\mathrm{f}$ & $\%$ \\
\hline Pemakaian KB IUD & Ya & 18 & 60 \\
& Tidak & 12 & 40 \\
Kejadian & Ya & 4 & 13 \\
Polymenorrhea & Tidak & 26 & 87 \\
\hline
\end{tabular}

Berdasarkan tabel 2. diketahui bahwa responden yang masih memakai alat kontrasepsi KB IUD adalah 18 orang (60\%) dan yang mempunyai riwayat pemakai $\mathrm{KB}$ IUD atau yang sudah melepaskan KB IUD sebanyak 12 orang (40\%). Diketahui juga pada tabel 2. bahwa responden yang mengalami kejadian Polymenorrhea sebanyak 4 orang (13\%) sedangkan yang tidak mengalami Polymenorrhea sebanyak 26 orang (87\%).

3. Hasil Analisis Bivariat

Tabel 3.

Pengaruh pemakaian KB IUD terhadap kejadian Polymenorrhea

\begin{tabular}{|c|c|c|c|c|c|c|c|}
\hline \multirow{3}{*}{$\begin{array}{c}\text { Peng } \\
\text { gun } \\
\text { aan } \\
\text { Kontra } \\
\text { sepsi }\end{array}$} & \multicolumn{4}{|c|}{$\begin{array}{c}\text { Poly- } \\
\text { menorrhea }\end{array}$} & \multirow{2}{*}{\multicolumn{2}{|c|}{ Total }} & \multirow[t]{2}{*}{$p$} \\
\hline & & /a & & & & & \\
\hline & $f$ & $\%$ & $f$ & $\%$ & $f$ & $\%$ & 0.079 \\
\hline KB IUD & 4 & 13 & 26 & 87 & 30 & 100 & \\
\hline
\end{tabular}

Berdasarkan tabel 3. diketahui bahwa responden yang mengalami polymenorrhea menggunakan kontrasepsi KB IUD sebanyak 4 orang (13\%), sedangkan yang tidak mengalami polymenorrhea sebanyak 26 orang (87\%). Hasil chi kuadrat didapatkan 0,079. Kesimpulannya adalah tidak ada pengaruh penggunaan KB IUD terhadap kejadian polymenorrhea pada responden penelitian di Puskesmas Mojolaban Kabupaten Sukoharjo.

\section{PEMBAHASAN}

1. Karakteristik Responden

a. Umur Berdasarkan karakteristik umur diketahui banyak responden pada rentang 2035 tahun sebanyak 15 orang (50\%). Umur seseorang juga dapat menggambarkan dari kematangan seseorang dalam menentukan segala sesuatu dari kehidupannya. Semakin usia mereka bertambah semakin matang pula mereka dalam menentukan suatu pemilihan, biasanya 
dipengaruhi juga karena pengalaman mereka. Usia subur yang aman untuk hamil antara umur 20 tahun sampai dengan 35 tahun (BKKBN, 2003). Pada penelitian ini dapat dilinat dari data distribusi frekuensi responden bahwa umur antara 20-45 tahun merupakan angka tertinggi yang mendominasi mereka untuk menyadari dalam menggunakan salah satu metode kontrasepsi IUD yang bila dilihat dari keefektifan maupun efek samping tidak jauh berbeda.

b. Pendidikan

Pada penelitian ini distribusi pendidikan responden menunjukkan bahwa semua responden tersebar pada semua tingkat pendidikan, dimana paling tinggi berpendidikan SMA sebanyak 10 orang (33\%). Tingkat pendidikan mempengaruhi kemampuan seorang untuk menerima atau memahami suatu pengetahuan, selanjutnya pemahaman seseorang tersebut berdampak pada sikap terhadap hal yang ada pada pengetahuan tersebut (Notoatmojo, 2007).

Seseorang yang mempunyai tingkat pendidikan tinggi akan memberikan respon yang lebih rasional dan juga dalam motivasi kerjanya akan berpotensi daripada mereka yang berpendidikan lebih rendah atau cukup. Pendidikan juga dapat diartikan merupakan tingkat dasar pengetahuan intelektual yang dimiliki seseorang. Pendidikan merupakan modal dasar dalam rangka pengembangan sikap dan ketrampilan. Pendidikan dianggap sebagai salah satu hal yang dapat mempengaruhi seorang calon akseptor untuk memilih metode kontrasepsi yang digunakan jenis kontrasepsi IUD.

c. Pekerjaan

Pekerjaan dalam arti luas adalah aktivitas utama yang dilakukan oleh manusia. Dalam artis sempit, istilah pekerjaan digunakan untuk suatu tugas atau kerja yang menghasilkan uang bagi seseorang. Pekerjaan dapat diartikan pula sebagai suatu kegiatan yang rutin dilakukan seseorang yang akhirnya dapat menghasilkan uang atau dapat mencukupi kebutuhannya secara sederhana ataupun secara kompleks. Distribusi pekerjaan responden didominasi sebagai swasta sebanyak 13 orang (43\%), sebagai ibu rumah tangga sebanyak 6 orang $(20 \%)$, sebagai buruh 5 orang (17\%), sebanyak wiraswasta 2 orang $(7 \%)$, sebagai PNS 4 orang (13\%). Responden yang bekerja maupun tidak bekerja tidak memilih kontrasepsi yang diinginkan tanpa melihat apakah latar belakang pekerjaan. Hasil penelitian menyatakan bahwa pekerjaan ibu tidak memiliki hubungan yang bermakna dengan pemakaian kontrasepsi KB IUD (Wulandari, 2013).

2. Analisa Univariat

a. Penggunaan Alat Kontrasepsi IUD

Tujuan dari pemakaian alat kontrasepsi adalah pencegahan kehamilan, pengendalian kehamilan yang dikonsep secara temporer yang bertujuan untuk mengatur jumlah anak yang dikandung atau yang lahir (Bobak dan Jensen, 2004). Responden penelitian juga 
mempunyai kesadaran diri tinggi telah berupaya untuk mengikuti program pengaturan jarak kehamilan. Berbagai latar belakang mereka yang berbeda tetapi telah berusaha untuk memilih dari berbagai macam metode Keluarga Berencana yang salah satunya adalah memilih kontrasepsi IUD sebagai pilihan yang terbaik untuk diri mereka sendiri dan keluarga.

b. Kejadian Polymenorrhea

Berdasarkan distribusi frekuensi responden dalam menggunakan alat kontrasepsi IUD yang mengalami polymenorrhea sebanyak 4 orang $(13 \%)$ sedangkan yang tidak mengalami polymenorrhea sebanyak 26 orang (87\%). Alat kontrasepsi IUD dapatmempunyai efek samping seperti terjadinya polymenorrhea. Keberadaan IUD berpotensi menimbulkan radang di rahim sebagai akibat memasukkan benda asing tersebut ke dalam rahim. IUD dimasukkan ke dalam endometrium atau lapisan dalam rahim mencegah telur yang sudah dibuahi untuk berkembang lebih lanjut menjadi janin. Dengan tetap berlangsungnya sistem reproduksi itu, keberadaan IUD didalam organ seolah menjadi benda asing, lalu beresiko membuat pembuluh darah membesar dan mudah berdarah. Inilah yang menyebabkan perempuan pengguna IUD mengalami pendarahan sebelum waktu menstruasi dan produksinya yang lebih banyak bisa pula dalam 1 bulan terjadi menstruasi sampai 2 kali dan waktunya yang lebih memendek, sehingga ini membuat perempuan yang tadinya tidak ada masalah dengan menstruasinya sekarang lebih peduli terhadap keadaannya, dan menjadi bermasalah dengan hal tersebut serta membutuhkan persediaan pembalut (Benson, 2009).

c. Pengaruh Pemakaian IUD terhadap Terjadinya Polymenorrhea

Berdasarkan hasil penelitian diketahui bahwa tidak terdapat pengaruh antara pemakaian IUD dengan kejadian polymenorrhea pada responden dengan taraf signifikansi yang digunakan adalah 95\% maka batas kritis 0,05 , sedangkan nilai $p=$ 0,079 , sehingga $\mathrm{Ho}=$ diterima, $\mathrm{Ha}=$ ditolak. Diketahui bahwa responden pemakai KB IUD sebanyak 18 orang (60\%) sedangkan yang tidak memakai atau mempunyai riwayat memakai KB IUD sebanyak 12 orang (40\%). Pemakai KB IUD yang mengalami polymenorrhea sebanyak 4 orang (13\%). Penggunaan KB IUD maupun kontrasepsi yang lain mempunyai keuntungan dan kerugian serta efek samping sendiri-sendiri. Keuntungan penggunaan KB IUD seperti AKDR dapat efektif segera setelah pemasangan, merupakan metode jangka panjang (10 tahun proteksi dari CuT-380A dan tidak perlu diganti), tidak ada efek samping hormonal dengan $\mathrm{Cu}$ AKDR (CuT-380A) serta tidak mempengaruhi ASI (BKKBN, 2010).

Responden dalam menggunakan kontrasepsi IUD sebenarnya mudah terinfeksi. Tali IUD yang berada di vagina, bertujuan untuk memudahkan proses 
pencabutan. Tali inilah yang berpotensi untuk dihinggapi oleh bakteri dan kemudian menjadi infeksi. Tanda terjadi infeksi salah satunya adalah mengalami nyeri di perut. Alasan ini pula yang menjadi dasar kenapa IUD sangat tidak dianjurkan untuk digunakan oleh perempuan yang belum pernah hamil dan melahirkan, karena ditakutkan rahim akan terinfeksi dan menyebabkan susah mendapatkan keturunan.

Dibandingkan dengan kontrasepsi sesama hormonal misalnya pil membutuhkan daya ingat yang lebih tinggi, sedangkan implant membutuhkan tindakan mini operasi yang kadang-kadang membuat responden menjadi trauma. Oleh sebab itu penggunaan IUD pada responden masih dianggap baik mengingat manfaat bagi pengguna lebih besar dari pada efek samping yang ditimbulkannya.

\section{KESIMPULAN}

1. Diketahui bahwa responden yang menggunakan KB IUD saat ini sebanyak $60 \%$ sedangkan yang tidak, maupun yang sudah melepas atau mempunyai riwayat pemakai KB IUD sebanyak $40 \%$.

2. Berdasarkan angka kejadian polymenorrhea pada responden terdapat wanita pemakai KB IUD yang mengalami polymenorrhea sebanyak $13 \%$.

3. Tidak terdapat pengaruh antara penggunaan KB IUD dengan kejadian polymenorrhea. Karena dikatakan normal apabila taraf signifikansi yang digunakan adalah 95\% maka batas kritis 0,05 , sedangkan nilai $p=0,079$, sehingga $\mathrm{Ho}=$ diterima, $\mathrm{Ha}=$ ditolak.

\section{SARAN}

1. Disarankan pada para akseptor KB untuk mempertimbangkan efek samping yang timbul sebelum memilih alat kontrasepsi yang akan dipergunakan.

2. Disarankan kepada petugas kesehatan di Puskesmas untuk memberikan konseling secara jelas kepada calon akseptor agar dapat memilih alat kontrasepsi yang sesuai.

\section{DAFTAR PUSTAKA}

Anggraeni, Y. dan Martin. 2012. Pelayanan Keluarga Berencana. Rohima Press, Yogyakarta.

Arintowati, Y. 2013. Pengaruh pemakaian Kontrasepsi IUD dengan kejadian Vaginitis Di Puskesmas Grogol Kabupaten Sukoharjo. Jurnal Kesehatan Profesi.

Profesional Islam. STIKES PKU Muhammadiyah, Surakarta.

Benson, C. R. 2009. Buku Saku Obstetri Dan Ginekologi. Edisi 9. EGC, Jakarta.

BKKBN. 2003. Usia Subur Kehamilan.

http://www.bkkbn.go.id.

Diakses 20 Januari 2014. . 2010. Buku Panduan Praktis Pelayanan keluarga Berencana.

http://www.bkkbn.go.id. Diakses 20 Januari 2014.

Bobak, L. dan Jensen. 2004. Buku Ajar Keperawatan Maternitas. Edisi4. EGC, Jakarta.

Departemen Kesehatan. 2012. Profil Kesehatan Provinsi Jawa Tengah, JawaTengah. http://www.depkes.go.id/downl oads/PROFIL KES PROVINS 2012/2013 Profil Kes. Prov. JawaTengah 2012.pdf. Diakses 23 Januari 2014. 
“Kosnเn“• JIK. Vol. 4 No. 2 September 2016

Manuaba. 2010. Ilmu Kebidanan, Penyakit Kandungan dan KB Untuk Pendidikan Bidan. Edisi 2. EGC, Jakarta.

Notoatmojo. 2007. Promosi Kesehatan dan umur perilaku. Rineka Cipta, Jakarta.

Wulandari, S., et al. 2013.

Hubungan Faktor Sosial
Budaya dengan Keikutsertaan

KB IUD.

http://www.respati.ac.id.

Diakses 22 Desember 2015.

${ }^{1}$ Dosen Akper Patria Husada Surakarta

2 Dosen STIKES PKU

Muhammadiyah Surakarta 